\title{
Empresas recuperadas: límites y potencialidades de la teoría gramsciana para su análisis
}

\section{Julieta Mascheroni $^{1}$ y Melina Perbellini ${ }^{2}$}

Fecha de recepción: 23 de julio de 2013

Fecha de aprobación: 11 de octubre de 2013

\begin{abstract}
Resumen
Podemos ubicar la emergencia de las empresas recuperadas en Argentina en el contexto abierto por la crisis orgánica (Gramsci, 2011) que se desatara en diciembre de 2001. Es en este contexto que los trabajadores decidieron defender sus puestos de trabajo, tomando las fábricas, para luego comenzar un proceso de recuperación y de puesta en producción de las mismas. Las empresas recuperadas implican una redefinición de las relaciones entre capital y trabajo y la puesta en acto de relaciones sociales fundadas en nuevos valores. El objetivo de este estudio es analizar el movimiento de las empresas recuperadas a partir de una perspectiva gramsciana, visualizando los límites y potencialidades de esta teoría para el análisis concreto de este fenómeno.
\end{abstract}

Palabras clave: Empresas recuperadas - Argentina - Gramsci

\begin{abstract}
Worker-recovered factories in Argentina are related to the context given by the organic crisis (Gramsci, 2011) that took place in December 2001. Workers decided to defend their workplace, took the factories and started a process of recovering their production. Recovered-factories entail a redefinition of the relationship between capital and labour and the development of social relations based on new principles. The objective of this study is to analyse the recovered-factories movement
\end{abstract}

1 Licenciada en Ciencia Política. Dirección postal laboral: Riobamba 250bis. E-mail: julietamascheroni@gmail.com Centro de Investigaciones y Estudios del Trabajo (CIET). Facultad de Ciencia Política y RR.II. Universidad Nacional de Rosario (UNR). Rosario. Argentina.

2 Licenciada en Ciencia Política. Dirección postal laboral: Riobamba 250bis. E-mail: melinaperbellini@gmail.com Centro de Investigaciones y Estudios del Trabajo (CIET). Facultad de Ciencia Política y RR.II. Universidad Nacional de Rosario (UNR). Rosario. Argentina. 
from a gramscian perspective, facing the limits and possibilities of this theory for the concrete analysis of such a phenomenon

Keywords: recovered factories; Argentina; Gramsci

\section{Introducción}

Podemos ubicar la emergencia de las empresas recuperadas en Argentina en el contexto abierto por la crisis orgánica (Gramsci, 1999) que se desatara en diciembre de 2001. Este ciclo coincidió con la irrupción de nuevas identidades colectivas que tornaron más complejo y variado el escenario donde se dirimen los intereses en conflicto.

Muchas empresas, tras haber sobrevivido al largo período de la convertibilidad, tambalearon durante la gran crisis, declarándose en estado de quiebra. Es en este contexto que los trabajadores decidieron defender sus puestos de trabajo, tomando, en primer lugar, las fábricas, para luego comenzar un duro proceso de recuperación de las mismas y su puesta nuevamente en producción.

Las empresas recuperadas implican una redefinición de las relaciones entre capital y trabajo y la puesta en acto de relaciones sociales fundadas en nuevos valores. Muestran que las relaciones sociales de trabajo, sin dejar de estar incorporadas en una sociedad donde el capital/trabajo sigue siendo su principal contradicción, han desandado las estructuraciones tradicionales y ofrecen un proceso de construcción de nuevas formas de asociatividad laboral.

El objetivo de este estudio es analizar el movimiento de las empresas recuperadas a partir de una perspectiva gramsciana, visualizando los límites y potencialidades de esta teoría para el análisis concreto de este fenómeno. Para esto nos centraremos en reflexiones de Antonio Gramsci en torno a la aparición de los Consejos de Fábrica en Turín en el año 1920, la noción de crisis orgánica para analizar el contexto de surgimiento de las empresas 
y los conceptos de democracia obrera y disciplina para analizar las tensiones internas de estos procesos una vez que la empresa es puesta en marcha.

Para este análisis utilizaremos las entrevistas abiertas en profundidad que hemos hecho a trabajadores de empresas recuperadas situadas en el área del Gran Rosario (Santa Fe-Argentina) desde el 2006 al 2012.

\section{Contexto de aparición de las empresas recuperadas: crisis del 2001 como crisis orgánica}

El surgimiento de las empresas recuperadas en Argentina luego de las jornadas del 19 y 20 de diciembre de 2001 no es azaroso. La crisis de 2001 puso fin, no sólo al modelo de acumulación basado en la valorización financiera (Basualdo, 2006), sino a la esencia misma del modelo de organización social neoliberal.

Es a partir del 2002 cuando el conflicto social se intensifica en nuestro país a partir de la aparición de los movimientos piqueteros, las asambleas barriales, los cortes de calles, y también las tomas de fábricas, que más adelante desencadenaron en las denominadas empresas recuperadas.

Siguiendo a Antonio Gramsci, planteamos que es éste un período de crisis orgánica; ya que se conjugan en él una gran crisis económica con una crisis de hegemonía de la clase dominante y una aguda crisis social, sin precedentes en Argentina, que marcó el principio del cambio de época.

La idea de cambio de época se la puede sostener a partir de la centralidad de dos fenómenos entrelazados: la emergencia de rasgos antagonistas en los movimientos sociales y el paralelo agotamiento de la hegemonía neoliberal. El cambio corresponde a una crisis de una forma de dominación, que tensiona y modifica una relación de poder, reestructurándola o superándola (Madonesi, 2008). 
El reordenamiento conservador, nacido a partir de la década del '90 con el denominado Consenso de Washington, se asentó por medio de la realización de un profundo proceso de reestructuración capitalista de corte neoliberal. Luego de la dictadura cívico-militar, el neoliberalismo pudo presentarse como un consenso inevitable y pretendió naturalizarse y diluirse en el sentido común. Fueron los años del "pensamiento único" que pretendía confirmar la ausencia de alternativas socio-económicas.

Gramsci plantea que la crisis orgánica abarca tanto la pérdida de supremacía intelectual y moral, como la posibilidad de los dominantes de hacer avanzar la economía, afectando a la estructura y a la hegemonía creada. Su solución puede venir desde abajo, pero también desde arriba. Es una crisis del Estado en su conjunto, donde la clase dirigente ve puesta en tela de juicio su autoridad, sea por un fracaso propio en una empresa política de envergadura, sea por la movilización activa y consciente de amplias capas sociales antes inactivas (Campione, 2007: 56).

Gramsci plantea que la forma particular de civilización, de cultura, de moral que la clase dirigente ha representado, se descompone con la desaparición de un modo de vivir y pensar que no puede producirse sin crisis (Campione, 2007). "La crisis consiste precisamente en el hecho de que lo viejo muere y lo nuevo no puede nacer: en este interregno se verifican los fenómenos morbosos más variados" (Gramsci, 1999: 37).

Es en este momento que se abren grandes posibilidades de que aparezcan alternativas ideológicas y políticas más "extrañas". Pero a su vez se generan condiciones para la introducción de transformaciones decisivas impulsadas "desde abajo", siempre que existan, activas y organizadas, fuerzas que puedan ser portadoras de esos cambios (Campione, 2007: 57).

Partiendo de esta lectura, planteamos que el desmantelamiento de la hegemonía neoliberal en nuestro país, desencadenó en una crisis orgánica que abrió las posibilidades de una disputa de poder. Es en este escenario de crisis, que surgen las empresas 
recuperadas como experiencias asociativas que cuestionan a la autoridad de la figura patronal en el momento en que este comienza a incumplir su rol en la relación capital/trabajo (al retirarse e intentar vaciar la fábrica). Los trabajadores deciden entonces la toma de las mismas, poniendo en tela de juicio la propia división capital/trabajo, patrón/trabajador.

En el próximo apartado nos centraremos en las reflexiones de Antonio Gramsci a raíz de la aparición de los Consejos de Fábrica en Turín en el año 1920, para tomar los elementos que nos sirvan para analizar a las empresas recuperadas, teniendo siempre presente la diversidad de los contextos de aparición de estas experiencias de autogestión.

\section{Consejos obreros y empresas recuperadas: diferentes experiencias de autogestión}

Gramsci realizó una importante reflexión sobre el proceso de autogobierno y autogestión obrera a partir del análisis del movimiento obrero acontecido entre 1919 y 1920 y que dio lugar a la formación de órganos de autogobierno específicamente obreros, los "consejos", que ya en 1920 alcanzan el control efectivo de las principales fábricas.

En este análisis gramsciano, podemos encontrar las primeras reflexiones sobre experiencias autogestivas que tomarán más relieve a partir de la experiencia Yugoslava de los 50, generando múltiples debates en torno a este concepto. Si bien no hay un consenso respecto de la definición del mismo, hay algo con lo que los diferentes autores concuerdan: "las experiencias autogestionarias siempre estuvieron relacionadas a las luchas de los trabajadores y, principalmente, del movimiento obrero" (Alburquerque, 2004: 41).

Específicamente, Gramsci se centrará en los procesos surgidos en Turín (Torino), una ciudad industrial (preeminentemente metalúrgica), caracterizada por la producción de automóviles. La 
principal empresa era Fiat, ocupando a más de treinta y cinco mil obreros.

En el contexto de la Europa de postguerra de los años '20, y como consecuencia de la adaptación de la industria bélica a una economía de paz, las ganancias obtenidas por los empresarios se redujeron importantemente. Buscando recuperarlas, redujeron salarios y despidieron a miles de obreros que respondieron ocupando los establecimientos y conformando Consejos de Fábrica en cada unidad productiva para controlar la producción, recogiendo la experiencia sovietista (Haidar, 2010; Ciolli, 2009).

Tal y como recopilará Fernández Buey (2001) de los escritos de Gramsci, los Consejos Obreros de esos años compartieron una serie de características, aun dentro de su diversidad. Entre las mismas pueden mencionarse:

$1^{\circ}$. La práctica de la democracia directa entre los trabajadores a través de la elección de delegados o representantes obreros en asambleas de taller y de fábrica;

$2^{\circ}$. La revocabilidad constante de los mandatos o delegaciones como forma de freno a la burocratización y el caciquismo;

$3^{\circ}$. El intento de superación de la división entre obreros organizados y no organizados sindicalmente, así como entre los diferentes niveles y categorías de la producción;

$4^{\circ}$. La superación de la organización obrera por oficios como forma de sindicación anticuada;

$5^{\circ}$. La afirmación de la primacía de la lucha en la fábrica y, por consiguiente, la necesidad de que la dirección de la lucha obrera estuviera en la fábrica misma;

$6^{\circ}$. El intento de demostrar la posibilidad de la gestión obrera de la producción con prescindencia de los capitalistas propietarios de los medios de producción.

El objetivo último de los Consejos de fábrica, y de su práctica autogestiva, sería abolir la distinción entre poder político y poder económico y lograr la emancipación y autonomía de los trabajadores considerados en su unidad, como productores, los cuales 
serán simultáneamente administrados y administradores, permitiendo su propio desarrollo orgánico. Es decir, la potencialidad de los Consejos deriva de su posibilidad de constituirse como órgano unificador de la clase en el lugar mismo de la producción, superando la escisión productor/ciudadano sobre la que la burguesía reproduce su dominación. Se trataría de creaciones revolucionarias que parten del lugar de trabajo y se cimentan en el momento de la producción (Laso Prieto, 1976). De este modo: "los consejos obreros, los soviets y otras experiencias similares fueron momentos extraordinarios en que los trabajadores ejercieron poder colectivo al interior de la fábrica pero con una fuerte proyección política hacia su exterior" (Ruggeri, 2010).

Estos Consejos nacieron en la fábrica, donde las relaciones de explotación son evidentes. Por ello, para Gramsci, su acción política puede trascender los límites de las relaciones contractuales. La democracia obrera llevada allí adelante es el modo de organización de la clase trabajadora (Ciolli, 2007: 175-176).

Nos dirá Gramsci que los sistemas de democracia obrera dentro de las fábricas se erigirían en escuelas de experiencia política y administrativa que darían forma y disciplina a las masas, encuadrándolas y brindándoles cohesión (Gramsci, 2004: 61). Es decir, los consejos obreros permitirían la práctica de nuevos mecanismos de gestión encaminados a la construcción de un nuevo sistema social y político.

Es así que el nacimiento de los Consejos de Fábrica representa, para el autor, un hito en un proceso histórico que culminará en la conformación de la Internacional Comunista y la consecuente reorganización de la economía y la convivencia humana a nivel mundial. Esto sucede en el sentido en que los mismos propician la fusión de los distintos equipos, secciones y momentos de la producción así como de las distintas unidades productivas. De este modo, para Gramsci el fin último de estas acciones era necesariamente la conformación del Estado obrero: "toda la clase 
obrera, tal como se encuentra en la fábrica, comienza una acción que tiene que desembocar necesariamente en la fundación de un Estado obrero, que tiene que conducir necesariamente a configurar una sociedad humana de una forma absolutamente original, de forma universal, que abarca toda la Internacional obrera, y, por tanto, toda la humanidad." (Gramsci, 2004: 79).

Siguiendo a Wyczykier (2009: 25), planteamos que para analizar la problemática de la autogestión es necesario realizar una diferencia entre: las experiencias autogestionarias que han buscado la instauración de un modelo social, político y económico que favoreciera la transformación y superación de las relaciones de dominación capitalista tal como pretendía Gramsci al analizar los Consejos de Fábrica surgidos en Turín; las experiencias de relaciones obreras democráticas en los países socialistas, como la experiencia yugoslava de la década del 50; y por último, las experiencias que se centran en la reproducción de prácticas autogestivas al interior de la esfera productiva sin connotaciones acerca de un cambio profundo de este modelo de acumulación, como parecería ser el caso de las empresas recuperadas.

Siguiendo esta última línea, sostendremos que las empresas recuperadas constituyen experiencias autogestivas que si bien no buscan, tal como pretendía Gramsci con los Consejos Obreros, un cambio social y político, se han tornado innovadoras al cuestionar la relación capital/trabajo. Del mismo modo, adherimos a la postura de Ruggeri (2010), quien sostiene que: “Interpretarlas en clave de reconstitución del sistema capitalista por no poder avanzar hacia la revolución socialista es menospreciar no sólo la experiencia y la lucha allí desarrollada (...) Y aún más importante que eso, es desconocer y despreciar los enormes sacrificios realizados por los trabajadores que consiguen hacer operar empresas abandonadas por los propios capitalistas".

Desde esta postura, buscamos observar cómo algunos ejes ya prefigurados por Gramsci operan en las empresas recuperadas y más específicamente en nuestros casos de estudio. Para esto 
retomaremos los elementos comunes a los Consejos previamente expuestos.

Fernández Buey (2001) nos marcará como un elemento común al funcionamiento de los Consejos la práctica de la democracia directa a partir de la elección de delegados en Asamblea. A este respecto, cabe recalcar que si bien en los casos relevados se respeta la instancia asamblearia para la toma de decisiones (propia del funcionamiento cooperativo), no todos los trabajadores se involucran del mismo modo, otros no participan de las mismas, y, en algunos casos, las instancias decisorias no se encuentran abiertas a la participación de todos los trabajadores de la empresa.

A partir de distintas entrevistas, hemos observado que algunos trabajadores, si bien votan en las elecciones de autoridades de la Cooperativa y toman parte de algunas decisiones asamblearias, no poseen un verdadero conocimiento acerca del funcionamiento de la Cooperativa. Del mismo modo, no participan de la toma de las decisiones más neurálgicas de la empresa ni de su área productiva. Algunas de estas cuestiones pueden observarse en los siguientes extractos de las charlas mantenidas con los trabajadores:

"A veces se hacen asambleas en que estamos todos. Pero si no, las decisiones las toman la directiva, el Consejo que hay. Las decisiones de los trabajos, o esas cosas, no las tomamos nosotros" (Trabajadora de empresa cristalera, 2010).

"El Consejo es el que decide junto con los directivos, son ellos los que realmente toman las decisiones" (Trabajadora de empresa cristalera, 2009).

Como contraparte, podríamos decir que al no haber participación de determinados sectores de la empresa en las decisiones, la dirigencia que toma estas decisiones tiende a autonomizarse y en algunos casos hasta volver a asumir la figura patronal. De este modo, vemos una continuidad entre las problemáticas plan- 
teadas en los años 20 por Gramsci y las que afectan hoy en día a estas experiencias autogestivas en relación con que la delegación produce la permanencia en los puestos de dirección de ciertos trabajadores, generando una burocratización interna y caciquismo, que podría ser evitado con la rotación de los mandatos.

Si bien podemos observar a partir de estos extractos que el funcionamiento asambleario dista de ser el ideal, nos interesa resaltar junto con Fernández y Borakievich (2007) que los dispositivos asamblearios de democracia directa que han asumido los trabajadores de empresas recuperadas, han sido una de las más fuertes condiciones de posibilidad para producir, inventar, recuperar nuevas disposiciones para la acción. Estos procesos, denominados de recuperación de la imaginación y la acción colectiva, "se vuelven posibles cuando las horizontalidades puestas en juego permiten el registro de las potencias deseantes de cada quien con otros, es decir, despliegan una corriente de fuerzas, de nuevas sinergias hasta entonces adormecidas en las lógicas fabriles tradicionales".

Prosiguiendo con nuestro análisis, resulta importante destacar que, a diferencia de los Consejos, las empresas recuperadas no surgen como parte de un proceso de reivindicación sindical, sino como consecuencia del quiebre de la relación salarial. De la misma forma, no se observa en estos procesos una proyección política y económica, sino una reacción ante la pérdida de las fuentes de trabajo y sustento. De este modo, podemos inferir las diferencias que generará en la voluntad y el deseo de estos trabajadores de ponerse a cargo del funcionamiento de la empresa. Otro tanto puede decirse acerca de la elección de la forma cooperativa de trabajo.

En el caso de las empresas recuperadas y, específicamente, en nuestros casos de estudios, la elección de la forma cooperativa de gestión se da por las exigencias legales a la hora de poner en marcha la producción para el sostenimiento de la fuente laboral. De acuerdo al marco legal, la Cooperativa de Trabajo se consti- 
tuye en el modo jurídico de legalizar su situación de ocupantes de la empresa fallida. No podemos de este modo hablar de la existencia de un proyecto socio-político ni de la re-elaboración de elementos simbólicos, cognitivos e ideológicos. Esto puede observarse en los siguientes fragmentos de charlas con trabajadores de estas empresas:

"Todos sabemos cómo surgen este tipo de empresas, que es en función de una necesidad, no en función del conocimiento y compartir ideas en común, sino que surge por la pérdida de trabajo de forma sistemática, por las distintas políticas de los gobiernos neoliberales" (Trabajador de cristalería, 2010).

"Nosotros no es que un día decidimos, bueno, vamos a trabajar todos juntos y ser socios porque realmente veíamos que esto iba a funcionar y que íbamos a formar una cooperativa. Nosotros formamos una cooperativa porque si no nos quedábamos todos en la calle y la única forma legal de seguir funcionando era como cooperativa, así que no fue una elección." (Trabajadora de empresa láctea, 2010).

"Esto se formó una cooperativa por un hecho de necesidad y no todos saben lo que es una cooperativa... nosotros no tenemos ese gran conocimiento de cooperativas, hicimos la cooperativa y lo único que hacemos es trabajar". (Trabajador de empresa de pastas, 2010).

Retomando otro de los elementos antes mencionados acerca del funcionamiento de los Consejos, específicamente el referido a la superación de la división entre diferentes niveles y categorías de la producción, nos interesa remarcar que la misma se constituye en otra compleja faceta de la constitución de la empresa como colectivo. Específicamente, a raíz de la persistencia de la separación tradicional de la empresa capitalista entre trabajo manual/ producción (trabajadores) y gestión/administración (patronal). Como marcábamos en trabajos anteriores (Dicapua, Marcheroni, 
Perbellini, Solero, Tavella, \& Valentino, 2011), para los trabajadores de producción, las tareas de gestión no son trabajo: tal como pensaban a su patrón, como no-trabajador. No se trata sólo de una cuestión funcional sino que en la misma entra en juego la construcción de su identidad como trabajador/productor, la cual se define por la oposición al patrón-no productor. Como señala uno de nuestros entrevistados: "nosotros estamos para trabajar y vivir, y hacer lo máximo posible, lo demás lo tiene que hacer la empresa, la gente que estás allá arriba..." (Trabajador empresa cristalera, 2007).

En el siguiente apartado, continuaremos el análisis de estas tensiones y conflictividades internas, a partir del concepto de disciplina propuesto por Gramsci.

\section{La democracia obrera y la disciplina en las empresas recuperadas}

Otra noción interesante que debemos rescatar para analizar las empresas recuperadas, es la relación que establece Gramsci entre disciplina y libertad. Para el autor, "adherirse a un movimiento quiere decir asumir una parte de la responsabilidad de los acontecimientos que se preparan, convertirse en artífices directos de esos acontecimientos mismos. (...) Disciplinarse es hacerse independiente y libre." (Gramsci, 2004: 23).

En este caso, la disciplina va a implicar un aprendizaje, un esfuerzo colectivo por parte de la clase trabajadora, una forma de potenciar las energías del pueblo trabajador. Esta disciplina es consciente y voluntaria porque cada uno participa con responsabilidad (Ciolli, 2009).

Para Gramsci, la masa obrera tiene que prepararse para conseguir el pleno dominio de sí misma, y el primer paso en este camino consiste en disciplinarse en la fábrica, de modo autónomo, espontáneo y libre. Es así que "la disciplina que pediréis a la masa obrera será distinta de la que el patrono imponía y pre- 
tendía basado en el derecho de propiedad que constituye en sí mismo una posición de privilegio. Vosotros os basaréis en otro derecho: el del trabajo." (Gramsci, 2004: 64-65).

Retomando estos conceptos para un análisis de las experiencias actuales, podemos observar que la disciplina como responsabilidad y compromiso aparece fuertemente en los discursos de los trabajadores de empresas recuperadas:

"Al principio yo tengo la sensación de que se produjo como una situación de anarquismo, cada uno creía que podía hacer las cosas, como que al no estar la figura patronal, como que no había nada, no hay leyes, no hay nadie que me diga qué tengo que hacer. (...) hasta que se dieron cuenta que no, que las cosas no eran así, que también ellos tenían su responsabilidad" (Trabajadora de empresa láctea, 2010).

“Necesitamos pautas de trabajo, necesitamos una organización, un ordenamiento, porque si no es imposible, es la única forma" (Trabajadora de fábrica de pastas, 2010).

Es necesario marcar que esta disciplina unida con libertad se distancia del disciplinamiento que impone el patrón basado en el derecho de propiedad. Esto lo vemos claramente en los discursos de los trabajadores de las empresas recuperadas:

“Ahora tenés más responsabilidad. Antes tu patrón te decía: depositá este cheque en tal banco y vos ibas y lo depositabas simplemente porque él te lo decía. Ahora tenés que decidir vos porque vos sos la responsable de esto" (Trabajadora de empresa cristalera, 2007).

“Si antes me decían a mí, mirá que esto es azul y yo sabía que no era azul, pero como era el dueño, yo le decía bueno, está bien. Ahora yo sé que es así y peleo porque sea así. Si el disco es redondo, sácalo redondo, no lo saqués cuadrado. Por eso peleo. Ahora siento más responsabilidad" (Trabajador de fábrica de pasta, 2010). 
En los Consejos de Fábrica, Gramsci observaba que una de las rupturas más importantes era que el Consejo se iba a nuclear de productores $-\mathrm{y}$ no de asalariados- orientados a dirigir el proceso de producción. Sin embargo, este paso en las empresas recuperadas no es nada fácil. Pensemos que los trabajadores han sido socializados en una relación salarial, conformando sus habitus desde ahí. Su socialización salarial de origen -marcada por una lógica fabril capitalista disciplinaria- aparece como un obstáculo a la hora de la construcción de su identidad como trabajadores autogestionados.

Tal como lo plantea Gramsci (2004: 80), el obrero tenía la convicción de la necesidad del propietario, cuya persona se identificaba con la persona del industrial, con la persona del gestor responsable de la producción y, por lo tanto, también de su salario, de su pan, de su ropa, de su techo.

Esto se ejemplifica claramente cuando un trabajador nos decía: "Yo no elegí dejar de ser asalariado, a mí no me entró en la cabeza que no soy más asalariado" (Trabajador de empresa láctea, 2012).

Tal como planteábamos en un artículo anterior, los trabajadores de empresas recuperadas no contaban con elementos simbólicos, cognitivos e ideológicos que les permitieran comprender la magnitud de la transformación emprendida: pasar de un conjunto de trabajadores asalariados, coordinados por la coacción y el disciplinamiento patronal a trabajadores autogestionados, autónomos para la organización y gestión productiva (Dicapua y otros, 2011).

Y esto, justamente, va a marcar dentro de la fábrica, los diferentes grados de compromisos que asumen los trabajadores. Ya que las empresas recuperadas devienen espacios complejos donde coexisten algunos rasgos de la empresa tradicional y, yuxtapuestos a aquellos, los propios de una comunidad de trabajo autogestionaria. 
Es lo que Fernández y Borakievich (2007) caracterizan como la emergencia de dos polos: la autogestión y en su opuesto la delegación. El compromiso va a oscilar entre dos extremos: el involucramiento en el proceso autogestionario (participación) o una actitud de acompañamiento (delegación). La actitud de acompañamiento pasa por reducir la participación a lo estrictamente acordado (las tareas según el puesto de trabajo), como podemos apreciar en los siguientes extractos de entrevistas:

“Querés que te diga la verdad, a mí me tienen al día. Yo cobro todos los sábados. No gano mucho, pero me pagan. No gano una locura pero cobro" (Trabajador de empresa cristalera, 2007).

"Yo sigo siendo empleado. Es decir, yo tengo que cumplir mi función. Por ejemplo, a mí me toca la parte de limpieza del comedor" (Trabajador de supermercado, 2006).

Esto pone en evidencia la socialización previa de estos trabajadores en un modelo salarial, creando habitus de clase que se exteriorizan en prácticas opuestas a estas nuevas formas de asociatividad en el trabajo y generando desde la operatividad del sentido práctico situaciones de conflicto y tensión, relacionado estrechamente con los diferentes grados de compromiso en el proceso.

"La idea que todos somos iguales, que estamos en el mismo equipo, no todo el mundo tiene puesta esta camiseta. Las peleas son cotidianas, no todos asumen el compromiso de la misma manera" (Trabajador de empresa láctea, 2012).

"No todos asumen la responsabilidad de la cooperativa, también. ¿Entendés? Todo está en ponerle ganas. Nosotros tenemos que madurar un poquito. Pero como te digo, no todos piensan igual, no todos asumimos la misma responsabilidad. No todos asumimos que esto es una cooperativa" (Trabajadora de empresa láctea, 2010) 
Si volvemos a la relación que establece Gramsci entre orden y disciplina, podemos observar junto a Ciolli (2009) que la consolidación de la democracia obrera responde a la necesidad de participación colectiva en las decisiones, y al mismo tiempo, a la necesidad de brindar orden y disciplina, que no va a significar la imposición por parte de un grupo, sino, por el contrario, es el aprendizaje y el esfuerzo colectivo por dar forma y potenciar las energías del pueblo trabajador. La democracia obrera permite que la disciplina sea consciente y voluntaria porque cada uno participó con responsabilidad, junto con los otros, en su comprensión y formulación.

En palabras de Gramsci, de a poco el trabajador va comprendiendo que la fábrica, nacida como ámbito de explotación y disciplinamiento, es el punto de partida de la liberación al quedar en manos de los legítimos productores de la riqueza, a través de su constitución en unidad homogénea y coherente (Campione, 2007, p. 27). Es "suscitar en la misma fábrica adecuadas secciones de instrucción, verdaderas escuelas profesionales en las que cada obrero, irguiéndose del cansancio que embrutece, pueda abrir la mente al conocimiento de los procesos de producción y mejorarse a sí mismo" (Gramsci, 2004: 65).

\section{Conclusiones}

El contexto de surgimiento de las empresas recuperadas en Argentina parte de la crisis orgánica acontecida en el 2001 que implicó la ruptura de la hegemonía neoliberal y dio pie a la aparición de diversas formas de contestación al orden político y económico reinante.

Con esta crisis orgánica la clase dirigente ve puesta en tela de juicio su autoridad, por un fracaso propio o por la movilización activa y consciente de amplias capas sociales. Este mismo cuestionamiento se puede ver reflejado en el momento en que los trabajadores deciden la toma de las fábricas a raíz del incumplimiento del rol patronal en la división capital/trabajo. 
Partiendo de las reflexiones propuestas por Gramsci en torno a los Consejos de Fábrica, pudimos tomar algunos elementos que nos sirvieron para pensar el funcionamiento de las empresas recuperadas hoy y las conflictividades para el funcionamiento de estas experiencias autogestivas.

De este modo, pudimos observar que el lugar primordial de la democracia directa, la Asamblea, muchas veces no es apropiado por todos los trabajadores constituyéndose en un ámbito más bien formal, antes que en un espacio de toma de decisiones. De este modo pudimos observar la persistencia de prácticas delegativas en algunos trabajadores, opuestas a las prácticas autogestivas que han intentado asumir otros trabajadores. Esto repercute a su vez en la cristalización en los puestos de dirección de las mismas personas, generando una tendencia a la reproducción de la división propia de la empresa tradicional: gestión (administración) - producción (trabajo).

Esto se encuentra íntimamente ligado a la persistencia del habitus asalariado que continúa actuando en las prácticas de los trabajadores. Es aquí donde puede apreciarse el tercer concepto abordado, el de disciplina, que nos permitió observar cómo varía el compromiso y la responsabilidad de los distintos trabajadores con la tarea común.

Por último quisiéramos mencionar que si bien no creemos pertinentes asignarles a estas experiencias autogestivas funciones ni intenciones de cambio global, es importante revalorizar las instancias de aprendizaje que generan.

Desde el ámbito del análisis científico-académico, acordamos con Ruggeri (2010) en que: “La oportunidad que representan las empresas recuperadas por sus trabajadores es hacernos visibles las potencialidades, y también los límites en las presentes circunstancias, de la autogestión como práctica económica y social y como proyecto de cambio del conjunto de la sociedad". 
Desde el ámbito de las experiencias concretas de los trabajadores, el aprendizaje se verifica en la posibilidad de ocupar nuevos cargos, con nuevas funciones y nuevas instancias decisorias, todos ellos ligados a la forma cooperativa de trabajo, permitiendo asumir el rol central del trabajador en la producción y gestión de las fábricas y modificando la relación capital/trabajo, propia del sistema capitalista. En palabras de una trabajadora:

"Lamentablemente no estábamos preparados para estar como consejo, para estar ocupando los cargos que tenemos ahora, lo aprendimos día a día, pero con esfuerzo, con la ayuda de todos estamos demostrando que se puede" (Trabajadora de empresa láctea, 2010).

\section{Bibliografía}

Alburquerque, Paulo (2004): “Autogestión” en Cattani, A. (comp.). La otra economía. Buenos Aires, Editorial Altamira.

Basualdo, Eduardo (2006): Estudios de historia económica argentina. Deuda externa y sectores dominantes desde mediados del siglo XX a la actualidad. Buenos Aires, FLACSO-Siglo XXI Editores.

Campione, Daniel (2007): Para leer a Gramsci. Buenos Aires, Centro Cultural de la Cooperación Floreal Gorini.

Ciolli, Vanesa (2009): La autogestión ayer y hoy - Una mirada desde el pensamiento de Antonio Gramsci. En A. Ruggeri, La economía de los trabajadores:autogestión y distribución de la riqueza (págs. 173-193). Buenos Aires, Ediciones de la Cooperativa Chilavert.

Dicapua, María; Mascheroni, Julieta; Perbellini, Melina; Solero, Carlos; Tavella, Mirta, y Valentino, Norma (2011): Empresas recuperadas: la conflictividad como condicionante de las formas autogestivas. Jornadas de Antropología Sociocultural. Perspectivas Críticas en la Antropología Contemporánea. Rosario, Facultad de Humanidades y Artes de la Universidad Nacional de Rosario.

Fernández, Ana María y Borakievich, Sandra (2007): Fábricas recuperadas. La anomalía autogestiva. Ponencia presentada en el 
Primer Encuentro Internacional de Debate: “La economía de los trabajadores: Autogestión y Distribución de la Riqueza". Buenos Aires, Facultad de Filosofía y letras. UBA.

Fernández Buey, Francisco: (10 de 04 de 2001). El proyecto ético-político de Gramsci. Obtenido de Centro de Investigación e Información Digital. En línea.

Gramsci, Antonio (1999): Cuadernos de la Cárcel. Tomo 2. México, Ediciones Era.

Gramsci, Antonio (2004): “Democracia Obrera”. En A. Gramsci, Antología (págs. 58-62). Buenos Aires, Siglo XXI.

Gramsci, Antonio (2004): “El consejo de fábrica”. En A. Gramsci, Antología (págs. 77-82). Buenos Aires, Siglo XXI.

Gramsci, Antonio (2004): “Disciplina y Libertad". En A. Gramsci, Antología (págs. 23). Buenos Aires, Siglo XXI.

Gramsci, Antonio (2004): “A los Comisarios de sección de los talleres Fiat-Centro y Patentes". En A. Gramsci, Antología (págs. 62-66). Buenos Aires, Siglo XXI.

Gramsci, Antonio (2004): “El consejo de fábrica”. En A. Gramsci, Antología (págs. 77-82). Buenos Aires: Siglo XXI.

Laso Prieto, José María (1976): Vigencia del pensamiento de Gramsci. EL BASILISCO, 73-83. S/D.

Madonesi, Massimo (2008): “Crisis hegemónica y movimientos antagonistas en América Latina. Una lectura gramsciana del cambio de época", en A Contracorriente. Vol 5. N 2 . NC State University.

Ruggeri, Andrés (2010): Autogestión en la Argentina: reflexiones a partir de la experiencia de las empresas recuperadas por sus trabajadores. Visioni LatinoAmericane è la rivista del Centro Studi per l'America Latina , 81-96.

Wyczykier, Gabriela (2009): De la dependencia a la autogestión laboral. Sobre la reconstrucción de experiencias colectivas de trabajo en la Argentina contemporánea. Buenos Aires, Prometeo. 